\title{
Universities, business and transferable skills
}

\author{
Government and the research councils have placed increasing emphasis \\ on the need for postgraduate students and postdocs to receive training in \\ business and commercial skills. But evidence of such training is patchy.
}

L ike the shotgun persuading a reluctant bridegroom to the altar, the policy of universities into the arms of industry and commerce. Money to finance the most recent initiative, the formation of centres of excellence for teaching business skills and the commercialization of research, was released this autumn.

The government sees the centres as important for instilling the right educational background into scientists and engineers who are intent on starting their own companies or keen to join large firms. "I don't think

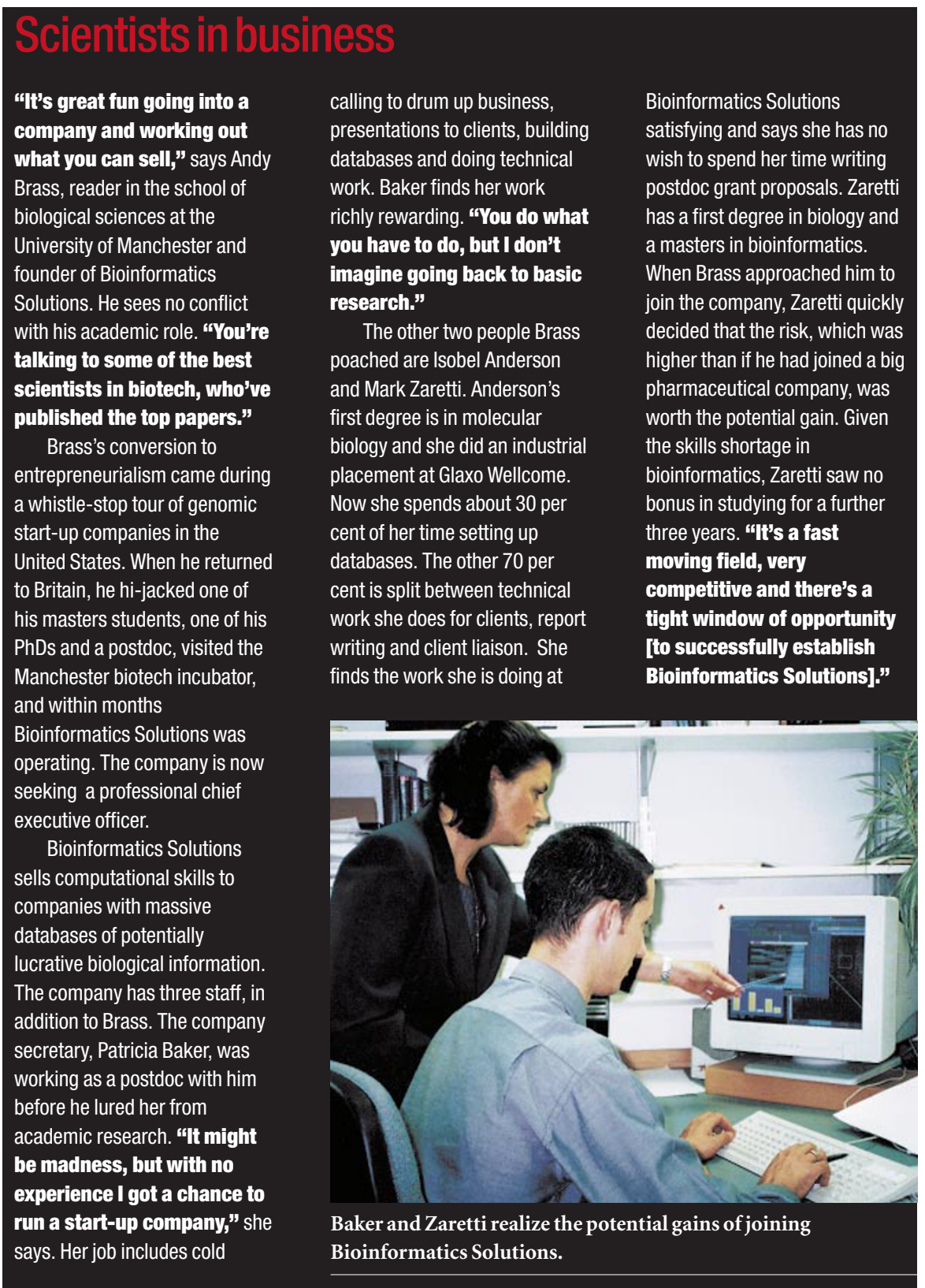

you can teach people to be entrepreneurs,' says Lord Sainsbury, the science minister, "but you certainly can teach them about basic things they need to know like intellectual property or venture capital."

The centres, for which government has set aside $£ 25$ million, are located at universities experienced in forming start-ups and in the commercial exploitation of research. They are seen as part of the foundation supporting - and here is the phrase that is flavour of the year - the knowledge-based economy.

\section{Commercial awareness}

Not all universities will have a science enterprise centre, but all are encouraged to teach the so-called transferable skills needed for life outside academic institutions as part of research masters (MRes) and $\mathrm{PhD}$ courses. The MRes courses, introduced as a pilot scheme in 1994 to equip undergraduates either for PhDs or for jobs in industry, are "the most heavily audited [by the research councils] in universities," says Richard Balment, the University of Manchester's director of graduate studies for biological science. Part of the audit evaluates the courses' effectiveness in training people in commercial awareness as well as in research.

Although the transferable skills element of an MRes is closely monitored for consistency, the record of inclusion of this training for $\mathrm{PhDs}$ is patchy. One way of assessing in advance whether your doctoral studies will offer a commercial dimension - should that interest you - might be to check whether your chosen university has a science enterprise centre.

Figures in a survey by the Engineering and Physical Sciences Research Council are revealing because they show a mismatch between what $\mathrm{PhD}$ students think would help them and the training they expect to receive (see Figure on p. A9). Only when it came to research methodology and presentation did more than 50 per cent of $\mathrm{PhD}$ students in the survey say they would receive training. In all other skills, fewer than 50 per cent expected any training, and less than 20 per cent reported they would be trained in entrepreneurship and innovation.

Yet such skills are essential, especially 


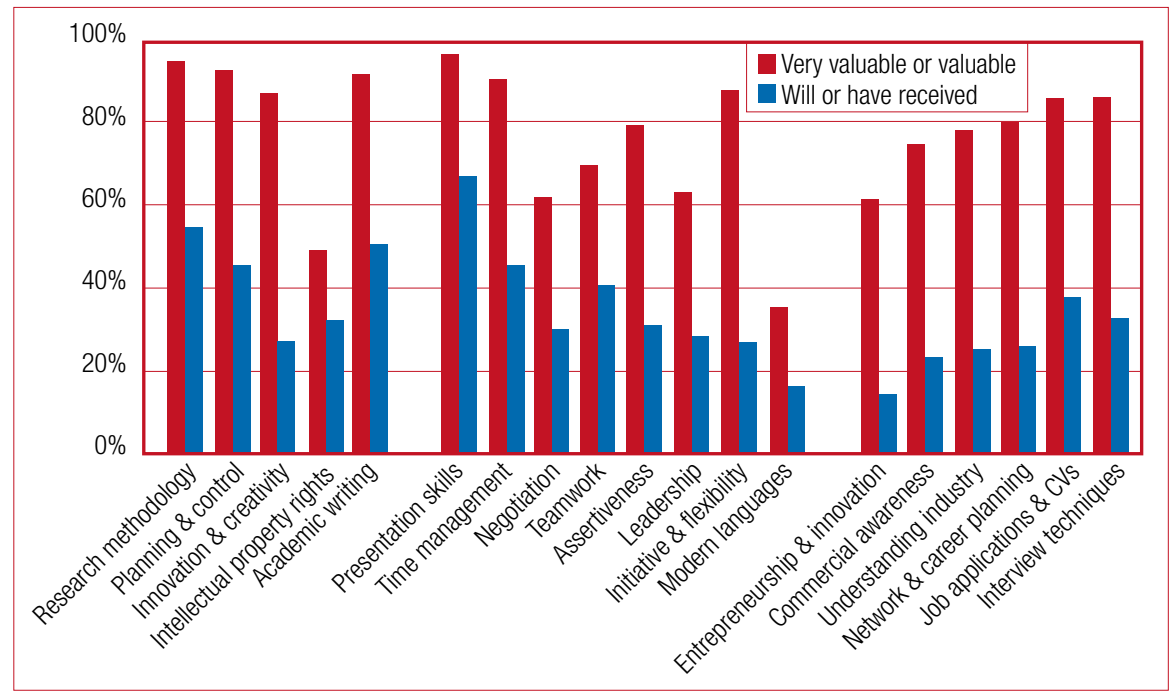

The value attached to different types of training by $\mathrm{PhD}$ students and their expectation of receiving that training at their university. (Source: EPSRC.)

given the supply and demand of academic jobs. "Training in methods of research should produce individuals capable of a variety of jobs. If a PhD fails in that, then it is wrong," says David Southwood, former head of the physics and astronomy department of Imperial College, London.

\section{Protecting intellectual property}

"Students need an awareness of the significance of patenting and protecting intellectual property," says Andy Brass, a reader in the school of biological sciences at the University of Manchester. Brass masterminded Manchester's MSc in bioinformatics and has himself turned entrepreneur, founding the company Bioinformatics Solutions (see Box on p. A8). Brass argues that students need to know how to keep lab notebooks to support a claim. In the United States, patents are awarded to the first to invent, so each page of a lab notebook needs to be countersigned every day. "You do this in an industrial lab, so you may as well learn the discipline during a PhD," says Brass. "It's

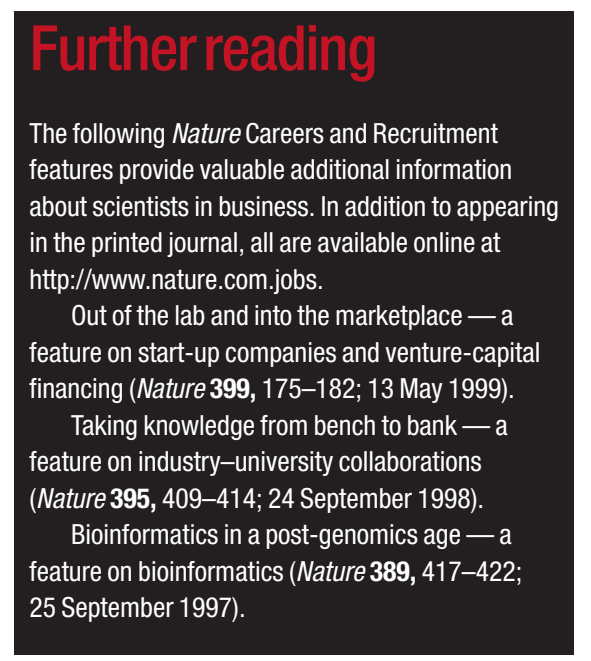

worth doing because if an idea is not protected by a patent, no one is going to invest in developing a product."

If skills training is offered on a patchy basis for $\mathrm{PhD}$ students, the situation is even more acute for postdocs. Yet this group faces serious dilemmas of short-term contracts, low pay and lack of career prospects in academic institutions.

Recognizing the unfairness of this position, the research councils, Royal Society, British Academy and the committee of vice chancellors and vice principals agreed in September 1995 to work for improved pay,

\begin{abstract}
here is, say physicists in industry, a mismatch between the skills needed in the private sector, including research, and those acquired while employed as a postdoc. Furthermore, although higher education institutions remain the main employers of physics postdocs, only a quarter of those surveyed could cite good examples of training and development in their universities.
\end{abstract}

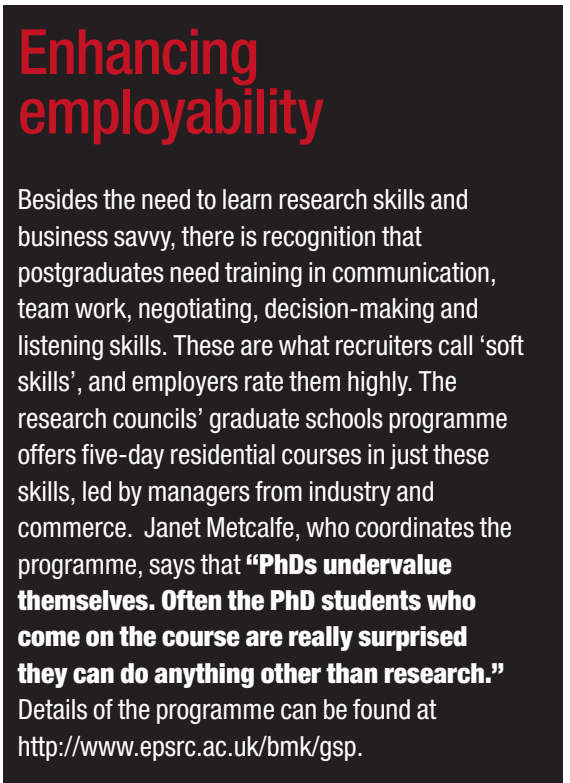

conditions and training for postdocs. "We are making some progress, but it's patchy," says Bob Price, head of human resources and development at the Biotechnology and Biological Sciences Research Council. Price attributes this to postdocs wanting to do academic research and not necessarily seeing the value of transferable skills, and to universities wanting to keep costs down. Given these circumstances, Brass argues that after one postdoc you should think seriously about what to do next: "If after one postdoc your position is not strong enough to get a fellowship, then re-evaluate."

\section{Where do all the postdocs go?}

\section{A survey of contract research staff by the Institute of Physics presents employment statistics of physics postdocs and has uncovered disturbing news about the need for wider skills training of postdocs in universities.}

The finding emerged in a study commissioned by the Institute of Physics (IoP) to find out what physicists do for a living and what are their aspirations and experiences. Published this summer, the survey results were based on responses from 448 people who started their first postdoc between 1988 and 1993. The survey team also questioned a group of 236 people who began their $\mathrm{PhD}$ between 1994 and 1995. All had experience 